\title{
SYNTHESIS, MAGNETIC MEASUREMENT AND SPECTROSCOPIC STUDIES ON COBALT (II) COMPLEXES WITH THIOSEMICARBAZONES DERIVED FROM P-ANISALDEHYDE, P-TOLUALDEHYDE, P-VANILLIN AND 9-FLUORENONE.
}

NARAYAN T. AKINCHAN

(Received 30 October, 2003; Revision accepted 5 May. 2003)

\section{ABSTRACT}

Cobalt(II) complexes, $\mathrm{Co}(\mathrm{ATSC})_{2} \operatorname{Co}(\mathrm{TTSC})_{2} \quad \mathrm{CO}(\mathrm{VTSC})_{2}$ and $\mathrm{Co}(\mathrm{FTSC})_{2}$ were prepared by reacting Cobalt(II)acetate and bidenlate thiosemicarbazones derived from p-anisaldehyde (ATSCH), p-tolualdehyde (TTSCH), p-vanillin (VTSCH), and 9-fluorenone (FTSCH) and were characterized by IR, uv-visible spectra, molar conductance, magnetic moment and elemental analysis. The, observed spectral data on thiosemicarbonzones indicate thione form for the ligands and they act as anionic bidentate chelating agents. The coordination takes place through thiolato sulphur and azonmethine /imine nitrogen atoms. The tetrahedral flattened structures have been suggested for the cobalt(II) complexes under investigation.

KEY WORD: Thiosemicarbazone, Cobalt(II) complex, IR, uv-visible, spectra, molar conductance, magnetic moment.

\section{INTRODUCTION}

Thiosemicarbanones have been used extensively for metal chelation in recent years and several reports dealing with spectral, structural and magnetic properties are available in literature. These reported results have been the subject matter for two reviews (Campbell, 1975, Padhye and Kauffman, 1985). This class of compounds has been found to show the antimicrobial activities (Klayman et al, 1979, Shipman et al, 1981. Ivanov et al 1989). There has been considerable interest shown in the coordination chemistry of cobalt(II) involving tridentate thiosemicarbanones (West and Galloway, 1988, Kumaret al 1993, Ferrari et $\mathrm{al}_{\mathrm{s}}$ 1986. Singh and Srivastav, 1988; West ef al, 1991, 1990, 1988, Pathak and Mishra, 1988). Only few reports are located in literature dealing with bidentate thiosemicarbazone cobalt(II) complexes. (Aganwala and Reddy, 1988, Balkrishnan and Aravindaksan, 1991). However, there are several reports on complexes of nickel(II) (Akinchan et al, 1992, Akinchan and Abram, 2000), platinum(II), (Akinchan ot al 1996, Akinchan and Akinchan 2002), copper(II) (Akinchan et al 1996), zinc(II) (Akinchan et al, 2002), cadmium(II) Akinchan et al. 2002) and mercury(II) (Akinchan et al 2000) with bidentate thiosemicarbazones. The present article describes the synthesis and characterization of cobalt(II) complexes of thiosemicarbazones derived from p-anisaldehyde, p-tolualdehyde, p-vanillin and 9-fluorenone, abbreviated as ATSCH, TTSCH, VTSCH and FTSCH respectively.

\section{MATERIALS AND METHODS.}

\section{Materials}

Cobalt(II)

thiosemicabazide p-tolualdehyde (L sodium acetate company. The other chemicals were chemically pure laboratory reagents.

\section{Synthesis}

Prepration of 9-fluorenone thiosemicabzone (FTSCH) To a boiling solution 9-fluorenone $(3.6 \mathrm{~g}, 20 \mathrm{~mol})$ in ethanol $(50 \mathrm{ml})$ was added dropwise to a solution of thiosemicarbazide $(1.82 \mathrm{~g}, 20 \mathrm{mmol})$ in ethanol $(50 \mathrm{ml})$. After adding five drops of glacial acetic acid, the resulting solution was refluxed for $2 \mathrm{hrs}$. On concentration to minimum volume and cooling at room temperature the yellow microcrystalline product was filtered washed and dried over silica gel. p-Anisaldehyde, (ATSCH) p-tolualdehyde (TTSCH) and p-vanillin (VTSCH) thiosemicarbazones were prepared using the same procedure, molar quantities and solution volumes as detailed for FTSCH above.

\section{Preparation of Cobalt(II) Complexes \\ Co(FTSC) $)_{2}$ Bis(fluorenone thiosemicarbazonato) cobalt(II) \\ FTSCH $(5.06 \mathrm{~g}, 20 \mathrm{mmol})$ was dissolved in ethanol} $(60 \mathrm{ml})$ by heating at reflux for $30 \mathrm{~min}$. To this solution was added $50 \mathrm{ml}$ ethanolic solution of $\mathrm{Co}(\mathrm{OAC})_{2} 4 \mathrm{H}_{2} \mathrm{O}(2.49 \mathrm{~g}$ $10 \mathrm{mmol}$ ) and the resulting solution was heated at reflux for another $2 \mathrm{hr}$ and left to cool at room temperature. The complex filtered off and washed with ethanol, diethyl ether and dried over silica gel. Co(ATSC) 2 ); Bis(anisaldene thiosemicarbanonato) Cobalt(II), $\quad \mathrm{Co}\left(\mathrm{TTSC}_{2}\right.$ bis(tolualdene thiosemicarbazonato) Cobalt(II)and Co(VTSC) 2 ; bis(vanillin thiosemicarbanato Cobalt(II) were prepared using the same procedure, molar quantities and solution volumes detailed for $\mathrm{Co}(\mathrm{FTSC})_{2}$ above.

\section{ANALYSIS}

Carbon, hydrogen and nitrogen were determined by standard micro methods at Regional Sophisticated Instrumental Centre, Central Drug Research Institute, 
Table 1: Empirical Formulas ${ }_{\text {, }}$ Colours, Melting / Decomposition Points, Partial elemental Analyses and Magnetic Moments of Cabalt(1I) complexes

\begin{tabular}{|c|c|c|c|c|c|c|c|c|}
\hline & Empirical Formula & Colour & Mp/dec & $\%$ found & Calcd) & & & peff \\
\hline & (Formula Weight) & & $\left({ }^{\circ} \mathrm{C}\right)$ & Co & C & $\mathrm{H}$ & $\mathrm{N}$ & BM \\
\hline $\operatorname{Co}(\text { FTSC })_{2}$ & $\begin{array}{l}\mathrm{C}_{10} \mathrm{C}_{28} \mathrm{H}_{20} \mathrm{~N}_{6} \mathrm{~S}_{2} \\
(563.57)\end{array}$ & $\begin{array}{l}\text { Yellow } \\
\text { green }\end{array}$ & 232 & $\begin{array}{l}10.28 \\
(10.46)\end{array}$ & $\begin{array}{l}58.44 \\
(59.67)\end{array}$ & $\begin{array}{l}3.40 \\
3.58\end{array}$ & $\begin{array}{l}14.76 \\
(14.91)\end{array}$ & 2.5 \\
\hline $\mathrm{Co}\left(\mathrm{TTSC}_{2}\right.$ & $\begin{array}{l}\mathrm{C}_{0} \mathrm{C}_{18} \mathrm{H}_{20} \mathrm{~N}_{6} \mathrm{~S}_{2} \\
(443.46)\end{array}$ & $\begin{array}{l}\text { Olive } \\
\text { green }\end{array}$ & 224 & $\begin{array}{l}13.18 \\
(13.29)\end{array}$ & $\begin{array}{l}48.35 \\
(48.76)\end{array}$ & $\begin{array}{l}4.32 \\
(4.55)\end{array}$ & $\begin{array}{l}18.78 \\
(18.95)\end{array}$ & 4.2 \\
\hline $\operatorname{Co}(\text { ATSC })_{2}$ & $\begin{array}{l}\mathrm{CoC}_{18} \mathrm{H}_{20} \mathrm{~N}_{\mathrm{G}} \mathrm{S}_{2} \\
(475.46)\end{array}$ & $\begin{array}{l}\text { Dirty } \\
\text { green }\end{array}$ & 196(D) & $\begin{array}{l}12.32 \\
(12.39)\end{array}$ & $\begin{array}{l}45.16 \\
(45.47)\end{array}$ & $\begin{array}{l}4.20 \\
(4.24)\end{array}$ & $\begin{array}{l}17.49 \\
(17.68)\end{array}$ & 3.4 \\
\hline $\operatorname{co}\left(\mathrm{VTSC}_{2}\right.$ & $\begin{array}{l}\mathrm{CoC}_{18} \mathrm{H}_{20} \mathrm{~N}_{6} \mathrm{~S}_{2} \mathrm{O}_{4} \\
(507.46)\end{array}$ & green & $185(D)$ & $\begin{array}{l}17.48 \\
(17.61)\end{array}$ & $\begin{array}{l}42.35 \\
(42.60)\end{array}$ & $\begin{array}{l}3.80 \\
(3.97)\end{array}$ & $\begin{array}{l}16.38 \\
(16.56)\end{array}$ & 3.6 \\
\hline
\end{tabular}

Di Decomposition:

Table 2: Selected IR bands $\left(\mathrm{cm}^{-1}\right)$ of thiosemicarbazones and cobalt(II) complexes

\begin{tabular}{|c|c|c|c|c|c|c|c|c|}
\hline FTSCH & $\mathrm{Co}(\mathrm{FT}, \mathrm{SC})_{2}$ & TTSCH & $\mathrm{Co}\left(\mathrm{TTSC}_{2}\right.$ & ATSCH & $\mathrm{Co}(\text { ATSC })_{2}$ & TVTSCH & Co(VTSC) $)_{2}$ & Assignment \\
\hline 3410 & 3430 & 3402 & 3418 & 3407 & 3410 & 3529 & 3525 & $\mathrm{~V}(\mathrm{OH})$ \\
\hline & & & & & & 3436 & 3440 & $\mathrm{~V}_{\mathrm{as}}\left(\mathrm{NH}_{2}\right)$ \\
\hline 3262 & $\ldots$ & 3242 & $\cdots$ & 3293 & $\cdots$ & 3277 & $\cdots$ & $\mathrm{V}(\mathrm{NH})$ \\
\hline 3156 & 3340 & 3158 & 3360 & 3159 & 3347 & 3154 & 3148 & $\mathrm{~V}_{\mathrm{s}}\left(\mathrm{NH}_{2}\right)$ \\
\hline 1600 & 1600 & 1598 & 1608 & 1607 & 1608 & 1595 & 1610 & \\
\hline 1490 & 1575 & 1541 & 1570 & 1557 & 1548 & 1540 & 1558 & $\mathrm{~V}\left(\mathrm{NH}_{2}\right)+\mathrm{V}(\mathrm{CN})$ \\
\hline 1469 & 1472 & 1511 & 1505 & 1538 & 1500 & 1510 & 1525 & V(NCS) \\
\hline 1433 & 1430 & 1463 & 1455 & 1470 & 1465 & 1460 & 1465 & \\
\hline 852 & 840 & 830 & 818 & 821 & 810 & 815 & 810 & $V(C=S)$ \\
\hline- & 655 & - & 766 & $\because$ & 778 & 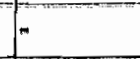 & 760 & \\
\hline- & $458 \mathrm{vbr}$ & - & 462 & F & 492 & F & $406 \mathrm{br}$ & $\mathrm{V}(\mathrm{CO}-\mathrm{N})$ \\
\hline- & 343 & - & 375 & $=$ & $390 \mathrm{br}$ & $=$ & 348 & $V(\mathrm{Co}-\mathrm{S})$ \\
\hline $\begin{array}{l}b_{r} \\
V_{e} \\
V_{s}\end{array}$ & $\begin{aligned} & = \\
& = \\
& =\end{aligned}$ & $\begin{array}{l}\text { Broad } \\
\text { Asynme } \\
\text { Symme }\end{array}$ & stretch & $\begin{array}{l}\text { bration } \\
\text { rration }\end{array}$ & & & & \\
\hline
\end{tabular}

Lucknow, India.

Physical measurement

Intrared spectra were obtained form Perkin Elmer

FTTR; 1800 spectrometer using standard $\mathrm{KBr}$ or Csl pellet technique for middle infrared region and nujol Mulls for far infared scanning. The reflectance spectra were recorded on a CARY 500-Scan UV-Vis-NIR spectrometer. The magnetic measuremnets were done as reported earlier (Akinchan et al 1996).

\section{RESULTS AND DISCUSSION}

The colour, partial elemental analyses empirical formula and magnetic moment values of cobalt(II) complexes are listed in Table 1. The lower conductivities for $10^{-3} \mathrm{~m}$ solution in DMF are in the range of $8-12 \mathrm{ohm}^{-1}$ $\mathrm{Cm}^{2}$ mole ${ }^{-1}$, which support non-electrolytic nature for the cobalt(II) complexes. (Geary, 1971. Balkrishnan andc Arvindakshan 1991). From the elemental analyses, the prepared cobalt(II) complexes could be formulated as $\operatorname{Co}(\text { ATSC })_{2}, \operatorname{Co}(\text { TTSC })_{2}, \operatorname{Co}\left(V_{T S C}\right)_{2}$ and $\operatorname{Co}\left(\mathrm{FTSC}_{2}\right.$. The structures of these cobatt(II) complexes along with ligand coordination mode will be discussed below:

\section{Infrared Spectra.}

Thiosemicarbazones used for chelation show several possible coordination sites, but two of them, namely azomethine or iminyl nitrogen and thiolate sulphur are usually involved (Akinchan, 2002). To confirm these phenomena four IR regions were investigated for thiosemicarbazones and their cobalt(II) complexes. Table 2 presents selected IR spectral bands along with tentative assignments based on previously reported literature data (Akinchan et al, 1992, 2002, West et al, 1991). In the spectra of thiosemicarbazones as $v(\mathrm{SH})$ band around $2500 \mathrm{~cm}^{-1}$ is absent but $\mathrm{v}(\mathrm{NH})$ is present in the region of $3242-3288 \mathrm{~cm}^{-1}$ indicating thione form in solid state. In addition, the ${ }^{1} H$ NMR Spectra of thiosemicarbazones under inrestigation does not show a signal at $4 \mathrm{ppm}$ attributed to S-H proton (Akinchan et al 1995).

At wavenumbers above $3100 \mathrm{~cm}^{-1}$, the thiosemicarbazones show three distinct IR bands in thes 

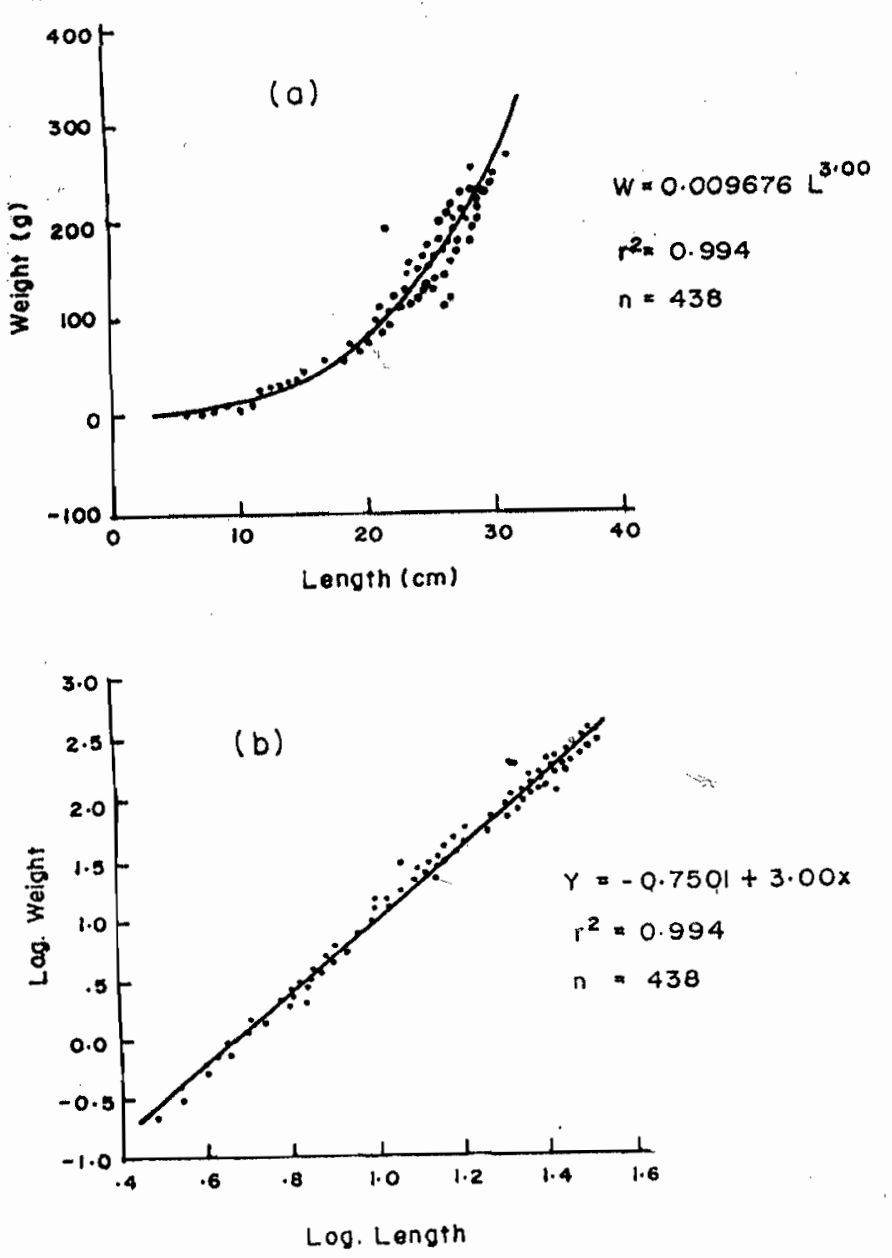

Fig. 2: Length-weight relationship in Ethmalosa fimbriata of the Cross River Estuary and adjacent coastal waters. - (a) non-linearized version (b) linearized version after log-. transformation.

as an assemblage, the Nigerian coastal water fishes exhibit allometric LWR, i.e. they tend to become thinner with increasing length. The result of the length-weight relationship in this study is in contrast with King (1996). The work of King (1996) drew the conclusion without the appropriate tool for test of significance. Secondly the sample size used was small and the range was low. The widest range was $15.5(15-31.5 \mathrm{~cm})$ and the smallest range was $2.9(8-10.9 \mathrm{~cm})$. In this study the minimum size was $3 \mathrm{~cm}$ and the largest size for LWR was $32.2 \mathrm{~cm}$ giving a very wide range of $29.2 \mathrm{~cm}$. The narrow size range in King (1996) was responsible for the erroneous conclusion, which included bonga of Nigerian coastal waters as exhibiting allometric growth.

It is interesting to find that the exponent b significantly departed from isometric condition for the separate sexes of bonga, but when the samples were merged together, the result showed that the exponent $b$ is isometric as it was exactly 3.00. There are two reasons for such a difference. The sample size when combined rose to 438 specimens. In the separate sexes the sample size were 109, 179 and 150 for males, females and juveniles respectively. According to Carlander (1969, 1977). values of $\vec{b}<2.5$ or $b>3.5$ are generally based on very small range of sizes and /or that such values are most likely erroneous. Therefore, the allometric condition shown by the separate sexes and the juveniles, is not a true picture of the LWR in bonga but is as a result of low size range and small sample sizes.

A characteristic of the length-weight relationship in fishes and invertebrates is that the value of the exponent (b) is 3 when growth in weight is isometric (without changing shape). If $b$ value is different from 3 , weight growth is said to be allometric (fish changes shape as it grows larger). Allometric growth may be negative $(b<3)$ or positive $(b>3)$.

Wootton (1992) indicated that allometric growth is negative $(b<3)$ if the fish gets relatively thinner as it grows longer and positive $(b>3)$ if it gets plumper as it grows longer. Thus some indication of the health condition can be obtained from the length- weight equation. In the present study result indicates that bonga does not change shape, as it grows larger.

Another characteristic of LWR is that where weight growth is isometric $(b=3)$, the parameter (a) can be interpreted as the condition factor of the fish by multiplying it by hundred (i.e. a.100), but if $b$ is not equal to 3 , the value (a) ceases to be an index of condition (Pauly, 1984; Enin, 1994). In the present analysis, the value of $b$ is 3.00 for Ethmatosa fimbriata. It is little wonder therefore that the use of parameter (a) as an index of condition for $E$ fimbriata (i.e. $C F=$ $0.0096761 \times 100$ ) gives a value of condition of 0.967 which is quite the same as the estimated value of Fulton's condition factor ( $C F=0.960$ ) obtained from mean length and mean weight in the sample.

It is not reasonable to describe the LWR of bonga tu be allometric for the separate sexes while it is clearly isometric for the combined sexes. Rather the results for the separate sexes should be termed as erroneous due to inability to satisfy the conditions for accurate calculation of the LWR. It is suggested that for a precise and concise estimation of the length-weight relationship in any species of fish, due consideration should be given to the sample size, making it as large as possible, and the entire size range of the population should be represented. These two requirements must be regarded as a standard in the calculation of the length-weiaht relationship.

\section{ACKNOWLEDGEMENT}

This work was supported by International Foundation for Science, Stockholm, Sweden, through grant provided to the author (Grant No. A 2914-1).

\section{REFERENCES}

Akpan, E. R., Offem, J. O., 1993. Seasonal variation in water quality of the Cross River, Nigeria. Rev. Hydrobio. trop. 26 (2): 95-103.

Ama-Abasi, D. E., 2002. Aspects of population biology of bonga, Ethmalosa fimbriata in Cross River 
values, and s.d. (y) is the standard deviation of the log $W$ values in the computation, $b$ is the estimated exponent of the LWR and $r^{2}$ is the coefficient of determination of the relationship. The value of $b$ is different from 3 if the calculated $t$ is greater than the tabled value of $t$ for the degree of freedom $n-2$ (Pauly, 1984).

\section{RESULTS}

The parameters of length-weight relationship and the condition factor calculated separately for juveniles, males and females of Ethmalosa fimbriata are given in Table 1.

The values of the exponent $b$, for the separate sexes and the juveniles show that the relationship is negatively allometric in the adult and positively allometric in the juveniles. The test for isometry, $\square$, indicates that the exponent $b$ for these different categories is significantly clifferent from 3 . But for the pooled data the test for isometry shows that the value $b$ is 3 , hence isometric condition.

Fig. 2 gives the relationship between length and weight in bonga of Cross River Estuary and adjacent coastal waters. Fig. 2 (a) is non-linearized fit of equation (1) to the data of length-weight relationship. Fig 2 (b) is the linearized approach to the same data after logtransformation. The relationship between weight and length in Ethmalosa fimbriata, with all categories combined i.e. from the pooled data, is defined by the linear regression model :

$$
\log W=-0.7501+3.00 \log L
$$

Which is also written as the power function model:

$$
W=0.009676 L^{3.00} ; a=0.009676, b=3.00, r^{2}=0.994
$$

A significant relationship was established, with the equation:

$W=0.000676 L^{3.00}\left(r^{2}=0.9941, t-\right.$ Test, $P<0.001, d . f=$ 436), and the length-wewight parameters estimated as $a=0.009676$ and $b=3.00$

The Fulton condition factor for the separate sexes is given also in Table 1. The Condition factor for the pooled data was the same as the parameter $a$.

\section{DISCUSSION}

The exponent $b=3.00$ in the length-weight equation for $E$. fimbriata indicates that $E$. fimbriata of the coastal waters off the Cross River estuary has an isometric weight growth (Bagenal and Tesch, 1978). This means that bonga grows al the same rate in all linear dimensions, i.e. increase in length; width and height are proportional to each other (Gayanilo and Pauly, 1997). Thus it is normal to use the conventional fish population dynamics models to analyze the population of bonga in the Cross River Estuary. Fagade and Olaniyan (1972) mentioned weight-length relationship of bonga but did not give the exact value of parameters in their study.

King (1996) reports the parameters of length-weight relationship of bonga from Cross River Estuary alongside those of other fish species and concluded that

Táble 1:

Parameters of length-wieight relationship and condition factor in different sexes of E. fimbriata.

\begin{tabular}{llllll}
\hline Sex & $a$ & $b$ & $r^{2}$ & $C F$ & $n$ \\
\hline & & & & & \\
Male & 0.0393 & 2.56 & 0.803 & 0.924 & 109 \\
Female & 0.022 & 2.73 & 0.844 & 0.950 & 179 \\
Juvenile & 0.0058 & 3.25 & 0.993 & 1.340 & 150 \\
Combined & 0.009670 & 3.0 & 0.994 & 0.960 & 438
\end{tabular}


Estuary and Adjacent Gulf of Guinea. Ph.D. Thesis, University of Calabar $179 \mathrm{pp}$.

Bagenal, T. B., Tesch, F. W., 1978. Age and growth. In: Bagenal Ted: Methods of Assessment of fish production in freshwaters. IBP Handbook No.3 Blackwell, Oxford: 101-136.

Boely, T. and Fieon, P., 1980. Coastal pelagic resources. In: J.P. Troadec and S. Garcia (eds). The Fish Resources of the Eastern Central Atlantic.Part1: The Resources of the Gulf of Guinea from Angola to Mauritania. FAO Fish Tech. Pap.186.1, pp13-76.

Carlander, K. D., 1969. Handbook of freshwater fishery biology. Vol 1. Life history data on Contrarchid Fishes of The United States and Canada lowa State Univ. Press, Ames. 431.

Carlander, K. D., 1977. Handbook of freshwater fishery biology. Vol II. Life history data on Contrarchid Fishes of The United States and Canada. lowa State Univ. Press, Ames. 752.

Dada, B.F. and . Gnanadoss, D.A.S., 1983. Nigerian fisheries development: Challenges and opportunities of the 1980s. Proceedings of the $3^{\text {rd }}$ Annual conference of The fisheries Society of Nigeria, 22-25 February, 1983, Maiduguri. Pp 14-24

Enin, U. I., 1994. Length-weight parameters and condition factor of two West African Prawns. Rev. hydrobiol. trop. 27(2): 1221-127

Fagade, S and Olaniyan, C.I.O., 1972. The biology of West African shad Ethmalosa fimbriata (Bowdich) in Lagos lagoon, Nigeria. J. Fish Biology 4, 519-533

Gayanilo, F.C. and Pauly, D. (eds)., 1997. FAO-ICLARM stock assessment tools (FiSAT). Reference Manual. FAO Computerized Information Series (Fisheries) No. 8. Rome, FAO. 262pp.

Irvine, F.R., 1947. Fish and Fisheries of Gold Coast Crown agent. London. 353pp
King, R. $P .1996$. Length-weight relationships of Nigerian coastal water fishes. NAGA. The ICLARM Quarterly. MCPO, 91(4): 53-58.

Longhurst, A. R.,1965. A survey of the fisheries resources of the Eastern Gulf of Guinea. , J. De Conseil 29, 302-334

Lowenberg, $U$ and Kunzel, $T ., 1992$. Investigations on the hydrology of the lower Cross River Nigeria. Anim. Res. Dev. 35: 72-85.

Pauly, D., 1984. Fish population in Tropical waters: a manual for use with programmable calculator. ICLARM, studies and Reviews.

Pauly, D., 1986. On improving operation and use of ELEFAN programs. Part 2. Improving the estimation of $L^{\infty}$. ICLARM Fishbyte 4(1): 18-20.

Pauly, D., 1993. Editorial: Fishbyte Section. NAGA, The ICLARM Quarterly 16 (2-3): 26

Sachs, L., 1974. Angewandle Statistik. Springer Verlag, Berlin.

Shotton, R., 1984. Preliminary assessment of the northwest African small pelagic fishery. CECAF project. INT/81/014.Dakar.110pp

Talarczak, K and Mizuuishi, I., 1976. Industrial marine fishes in CECAF Area. Part 1. Morocco to Liberia, CECAF/RTECH/ \& 6/3, 65

Williams, F., 1975. Fishery resources of the tropical Eastern Central Atlantic Ocean: exploration, utilization and mi, ragement since 1960. Bruun memorial lectures presented at the8th session of the IOC Assembly, UNESCO, and 5-11 November 1973, at Paris, IOC Tech.Ser.No11.

Wootton, R.J., 1992. Fish ecology: Tertiary level biology. Blackie 